\title{
Influence of the protocol of fibroin extraction on the antibiotic activities of the constructed composites
}

\author{
Wafa I. Abdel-Fattah ${ }^{1} \cdot$ Nagwa Atwa $^{2} \cdot$ Ghareib W. Ali $^{1}$
}

Received: 11 March 2015/Accepted: 12 June 2015/Published online: 4 July 2015

(c) The Author(s) 2015. This article is published with open access at Springerlink.com

\begin{abstract}
The effect of the solvents for silk fibroin (SF) extraction on its antimicrobial activity was studied. Extraction protocols were performed using $\mathrm{LiBr}\left(\mathrm{SF}_{\mathrm{L}}\right)$ and $\mathrm{Aji}$ sawa's reagent $\left(\mathrm{CaCl}_{2}\right.$ :ethanol: $\left.\mathrm{H}_{2} \mathrm{O}\right)\left(\mathrm{SF}_{\mathrm{C}}\right)$. The morphological and structural characteristics of the extracted $\mathrm{SF}$ and their composites were assessed. Corresponding bactericidal activities against Staphylococcus aureus (ATCC 25923), Escherichia coli (ATCC 25922) and Pseudomonas aeroginosa (ATCC 27853) were performed. The resulting solutions were either casted into films or individually incorporated into composites of silver nanoparticles (NS) embedded into chitosan fragments (Cs) through $\gamma$-irradiation. Films of SF, obtained by using the two solvents, as well as the final prepared composites of SF, NS and Cs were analyzed using XRD, FTIR, SEM, TEM and zeta potential at several $\mathrm{pH}$ values. The band gap values were calculated. The results proved that, although $\mathrm{SF}_{\mathrm{C}}$ consumed shorter gelation time, yet $\mathrm{SF}_{\mathrm{L}}$ exerted higher antibiotic activity against the tested microorganisms. Moreover, the final composites had the ability to significantly reduce the growth of these medically relevant bacteria and are, therefore, recommended as a novel natural antibacterial biomaterial for several biomedical applications.
\end{abstract}

Wafa I. Abdel-Fattah

nrcfifi@yahoo.com

Nagwa Atwa

nagwaatwa@yahoo.com

Ghareib W. Ali

wafaaghareib@gmail.com

1 Biomaterials Department, National Research Centre, Tahrir St. Dokki, Cairo, Egypt

2 Chemistry of Natural and Microbial Products Department, National Research Centre, Tahrir St. Dokki, Cairo, Egypt
Keywords Silk fibroin · Nanosilver ·

FTIR-deconvolution · Bactericidal activity $\cdot$ Band gap

\section{Introduction}

Biomaterials have been increasingly applied to improve surgical procedures of missed bones to restore the quality of life. Several millions of patients worldwide need bone grafts and other orthopedic as well as dental surgeries. The demand for biomaterials increases every year. It is crucial that these devices should be non-toxic, biocompatible and non-immunogenic.

Silk has been used for thousands of years in the textile and for about a century for suture materials. Recently, silk is reported as one of the most chosen candidates for biomedical applications since it exhibits biodegradability and environmental stability with excellent mechanical properties (Altman et al. 2003).

The domesticated silkworm, Bombyx mori, spins silk with distinctive properties. An insoluble protein, silk fibroin and glue-like protein, sericin, combined to form the silk. It is composed of three components: heavy $(\mathrm{H})$ chain fibroin $(350 \mathrm{kDa})$, light $(\mathrm{L})$ chain fibroin $(25 \mathrm{kDa})$ and P-25 protein in a molar ratio of 6:6:1, respectively. Structural analysis of the $\mathrm{H}$-chain possesses two types of molecular conformations being $\alpha$ - and $\beta$-helix. The former is non-crystalline and soluble in water while the later is highly stable organized and insoluble in water (Motta et al. 2002). Silk I is mainly formed of $\alpha$-helix sheets, while that containing a higher percentage of $\beta$-helix is termed silk II (Inoue et al. 2000).

Silk fibroin is an approved FDA product for many applications such as surgical sutures (Rujiravanit et al. 2003), drug delivery components and tissue engineering 
(Sofia et al. 2001) beside burn wound dressings (Santin et al. 1999), enzyme immobilization matrices (Acharya et al. 2008), vascular prostheses and structural implants (Dalpra et al. 2005; Meinel et al. 2005). However, some concerns have been raised regarding the use of silk as a medical biomaterial since several adverse immune responses, caused by sericin as well as the wax-like material found on the fibers, were reported (Nagarkar 2010). However, pure silk fibroin constructs are reported to be biocompatible, biodegradable with minimal inflammatory reactions (Altman et al. 2003). Such pure silk fibroin is obtained by the degumming of silk fibers where the aqueous solution of the protein is converted into several biomaterial forms such as hydrogels, films, sponges and non-woven mats (Vepari and Kaplan 2007).

Silk fibroin hydrogel is reported to have considerable attention for drug delivery and tissue engineering applications (Hanawa et al. 1995; Fini et al. 2005). The gel strength and gelation rate were reported to be greatly dependent on the $\mathrm{pH}$ and solution concentration. When the electrostatic repulsion between the macromolecules is sufficiently reduced at the isoelectric point of silk fibroin (pH 3.8-3.9) gelation occurs (Haider et al. 1992). Interestingly, the low-pH-induced silk fibroin hydrogel proved to impart better healing results when used as bone filling biomaterial (Fini et al. 2005).

A true solution of SF protein is very difficult to obtain due to its high molecular weight (500-750,000 Da) and its crystallinity, caused by the intermolecular hydrogen bonds, as well as its hydrophobic nature (Simmons et al. 2006). Various techniques were proposed to dissolve silk fibroin. These involved the use of harsh, chaotic solvents such as strong acids or ionic concentrated salt solutions. Scientists used concentrated sulphuric, hydrochloric or nitric acids to dissolve the fibers (Sonthisombat and Peter 2004). Moreover, different ionic liquids including $\mathrm{LiBr}$ (Chen et al. 2001), $\mathrm{CaCl}_{2}$ or Ajisawa's reagent (Liang and Hirabayashi 1992), calcium nitrate in methanol (Mathur et al. 1997), aqueous lithium bromide and ethanol (Matsumoto and Uejima 1997; Matsumoto et al. 1997), aqueous lithium thiocyanate (Agarwal et al. 1997) and aqueous sodium thiocyanate (Sun et al. 1997) were reported.

The aim of the present work was to study the dissolution of silk fibroin, from Bombyx mori, using either $\mathrm{LiBr}$ solution or Ajisawa's reagent as models of ionic liquids. The obtained solutions were casted into films and their antibacterial activities, against medically relevant gram positive and negative bacteria were compared. The silk fibroin obtained by either protocol was incorporated into a nanosilver/chitosan composite (Ag6d3), previously synthesized and assessed by our team (Abdel-Fattah et al. 2014). The two solvents were selected as they feature the most common protocols applied in silk fibroin extraction.
Salvador et al. (2013) studied the effect of extraction protocol on the chemical and mechanical properties of the obtained silk fibroin. However, studies on the influence of extraction protocol on silk fibroin bactericidal activity are rare. The present work is concerned with tackling this deficiency. According to the future biomedical demand, the extraction protocol could be selected as extraction by the Ajisawa's reagent will need shorter gelation time. On the other hand, extraction protocol with $\mathrm{LiBr}$ will result in more efficient bactericidal functions.

\section{Materials and methods}

\section{Materials}

Silk fibroin was extracted from Egyptian Bombyx mori (Silkworm). Purchased chemicals were sodium carbonate (Fine-Chem. LTD), lithium bromide (M.wt., 86.845, $99 \%$, Molychem.), calcium chloride (M.wt. 110.99 g, $98 \%$, ADWIC), chitosan (85\% deacetylated, Oxford chemical Co), silver nitrate (M.wt. 169.87 g, $99.8 \%$, Fine-Chem. LTD), glutaraldehyde (50\%, ADWIC), acetic acid and isopropanol (analytical grade). All solutions were prepared in bidistilled water. Dialysis membrane, MWCO 3500 kDa (Pierce, Rockford, IL, USA) was used.

The antibacterial activities of the developed films and composites were tested against Staphylococcus aureus (ATCC 25923), Escherichia coli (ATCC 25922) and Pseudomonas aeroginosa (ATCC 27853) purchased from American Type Culture Collection (ATCC, Manassas, VA). Strains were cultivated in Mueller-Hinton (MH) broth (Guangdong Huankai Microbial Science and Technology Co Ltd, Guangzhou, China).

\section{Methods}

\section{Silk fibroin extraction}

Silk fibroin degumming process Egyptian Bombyx mori cocoons weighing $20 \mathrm{~g}$ (pupae and inner envelope removed) were degummed to remove the sericin. Degumming was performed by boiling for 3 consecutive times, $1 \mathrm{~h}$ each, in an aqueous solution of $\mathrm{Na}_{2} \mathrm{CO}_{3}(1 \mathrm{~g} / \mathrm{L})$. Degummed silk was then washed several times with bidistilled water and oven dried at $40{ }^{\circ} \mathrm{C}$ (Salvador et al. 2013). Continuous boiling was avoided to prevent sericin accumulation in the degumming solution.

Silk fibroin dissolution The extraction routes using either LiBr solution $(9.3 \mathrm{M})$ or Ajisawa's reagent composed of $\mathrm{CaCl}_{2}: \mathrm{C}_{2} \mathrm{H}_{5} \mathrm{OH}: \mathrm{H}_{2} \mathrm{O}$ in 1:2:8 molar ratios were compared in concentration of $10 \% \mathrm{~W} / \mathrm{V}$ and designated as $\mathrm{SF}_{\mathrm{L}}$ and $\mathrm{SF}_{\mathrm{C}}$, relevant to $\mathrm{LiBr}$ and Ajisawa's reagent, respectively 
Fig. 1 Silk fibroin (SF) degumming and dialysis processes for obtaining $\mathrm{SF}$ solutions

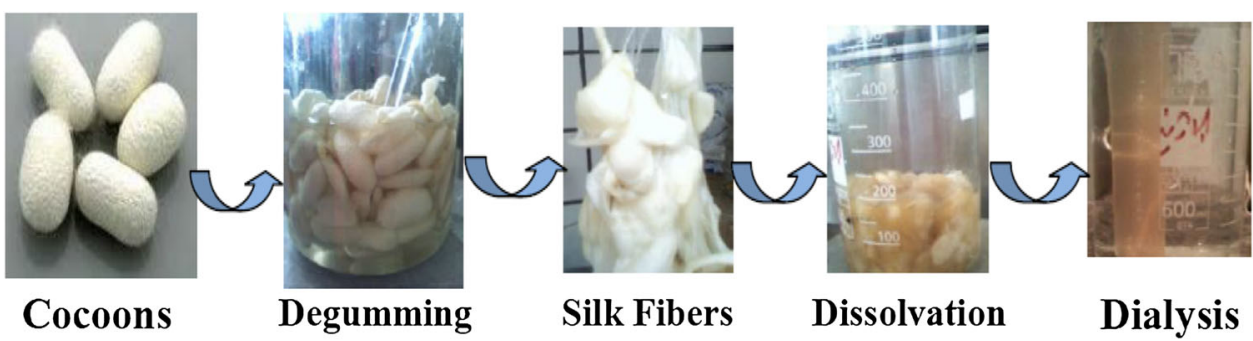

placed on a carbon-coated copper grid. Samples were left to dry at ambient temperature.

Zeta potential values were measured using the laser zeta meter (Malvern zeta seizer). A silver chitosan nanoparticles aqueous solution $(10 \% \mathrm{~W} / \mathrm{V})$ including $\mathrm{NaCl}$ as a suspending electrolyte solution $\left(2 \times 10^{-2} \mathrm{M}\right)$ was prepared. The $\mathrm{pH}$ was adjusted to the required values (HANNA $\mathrm{pH}$ meter 211). The samples were shaken for $30 \mathrm{~min}$, the equilibrium $\mathrm{pH}$ was recorded and the zeta potential measured. An average of three separate measurements was obtained.

\section{Antimicrobial activity testing}

Bacterial cell suspensions were prepared, for each tested bacterial culture, using sterile normal saline solution $(0.9 \% \mathrm{w} / \mathrm{v} \mathrm{NaOH})$ to obtain a final concentration of $10^{7} \mathrm{CFU} / \mathrm{ml}$ by comparison with a $0.5 \mathrm{Mc}$ Farland turbidity standard. Equal weights of each film were individually inserted in test tubes, each containing $10 \mathrm{ml}$ of sterile Mueller-Hinton (MH) broth (composed of g/l: beef extract, 2.0; casein hydrolysate, 17.5 and starch $1.5 ; \mathrm{pH} 7.3 \pm 0.2$ ). The medium, supplemented with the samples, was sterilized by autoclaving for $20 \mathrm{~min}$ at $120{ }^{\circ} \mathrm{C}$ and 1.5 atmospheric pressure. After sterilization, each test tube was inoculated with $100 \mu \mathrm{l}$ of one of the previously prepared bacterial suspensions and then incubated under moderate shaking of $100 \mathrm{rpm}$ at $35{ }^{\circ} \mathrm{C}$ for $24 \mathrm{~h}$ (treated microorganisms). Controlled test tubes, containing the same volume of $\mathrm{MH}$ medium free of composite films, were inoculated as well using the same inoculum size of the tested strains (untreated microorganisms). The cell growth of the tested bacteria was determined at the end of the incubation period, based on the optical density measurements at a wavelength of $620 \mathrm{~nm}$ (CE 595 double beam spectrophotometer. Cecil instrument). Results were expressed in terms of their cell dry weight (CDW) using the relation between the optical density of the cell and their cell CDW (Abdel-Fattah et al. 2014).

\section{Morphology of films bacterial cultures}

The film specimens were rinsed twice with phosphate buffer solution ( $\mathrm{pH} 7.0)$ to remove culture media residues ultrasonic homogenizer for $6 \mathrm{~min}$, and then one drop was 
and the samples fixation was performed as previously reported (Abdel-Fattah et al. 2014). Finally, the specimens were mounted on copper stubs with double-sided adhesive tape, coated with gold (S150A Sputter coated EdwardsEngland) and then scanned by SEM (JXA-840A Electron probe micro analyzer-Joel-Japan).

\section{Results}

\section{Aqueous solubility of silk fibroin}

The results showed that $\mathrm{LiBr}$ was able to completely dissolve the silk fibroin fibers in a relatively short time $(2 \mathrm{~h})$ while the Ajisawa's reagent needed double incubation time $(4 \mathrm{~h})$. After dialysis, the solutions were filtered. The total solid protein concentration of $4 \%(\mathrm{~W} / \mathrm{V})$ was achieved through drying a known volume of silk fibroin solution and weighting.

\section{Silk fibroin gelation}

In order to test for the optimum conditions for the preparation of the $\mathrm{SF}_{\mathrm{L}}$ and $\mathrm{SF}_{\mathrm{C}}$ gels, corresponding solutions were adjusted at several $\mathrm{pH}$ values between 2.5 and 5.0 and kept at $4{ }^{\circ} \mathrm{C}$ The gelation time was monitored for about $300 \mathrm{~h}$. The results (Table 1) showed that the SF solutions gelling depended strongly on their $\mathrm{pH}$ values. $\mathrm{SF}_{\mathrm{L}}$ stable gels were achieved at $\mathrm{pH}$ values of 3.5 and 4.0 at 192 and $240 \mathrm{~h}$, respectively. However, although solutions of $\mathrm{SF}_{\mathrm{C}}$ formed stable gels at the same $\mathrm{pH}$ values, it consumed much shorter periods corresponding to 48 and 168 at the $\mathrm{pH}$ values mentioned above. A lower $\mathrm{pH}$ value of 2.5 resulted in an obviously unstable gels for both $\mathrm{SF}_{\mathrm{L}}$ and $\mathrm{SF}_{\mathrm{C}}$ solutions. Also, a much higher incubation time was recorded for the stable gels formation at $\mathrm{pH}$ higher than tested up to 5 (Fig. 2).

\section{UV-Vis spectroscopy}

Strong bands at 274 and $278 \mathrm{~nm}$ characteristic for $\mathrm{SF}_{\mathrm{L}}$ and $\mathrm{SF}_{\mathrm{C}}$, respectively, appeared in Fig. 3a. Chen et al. attributed theses peaks to the $\pi \rightarrow \pi^{*}$ electron transition of the amino acid residues in protein chain of silk fibroin (Autran

Table 1 Gelation times (h) at their corresponding $\mathrm{pH}$ values

\begin{tabular}{lrrrrrr}
\hline Gelation time (h)/samples & $\mathrm{pH}$ & & & & & \\
\cline { 2 - 7 } & 2.5 & 3.0 & 3.5 & 4 & 4.5 & 5 \\
\hline $\mathrm{SF}_{\mathrm{L}}$ & 168 & 176 & 192 & 240 & 261 & 287 \\
$\mathrm{SF}_{\mathrm{C}}$ & 40 & 48 & 48 & 168 & 190 & 210 \\
\hline
\end{tabular}

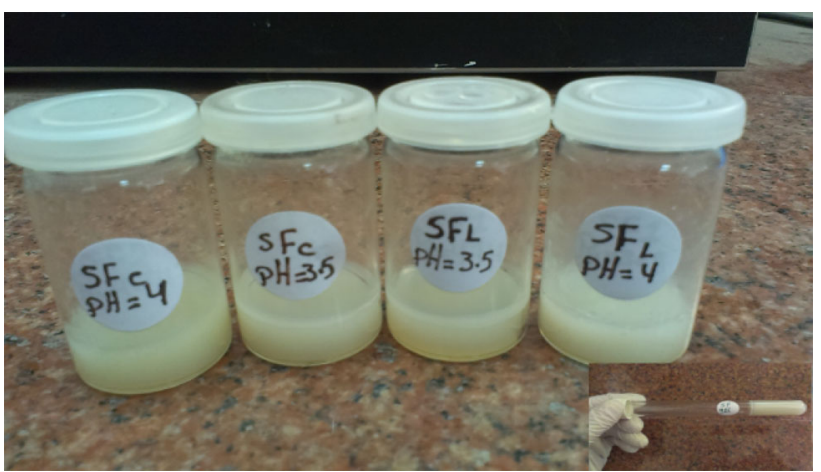

Fig. 2 Silk fibroin hydrogels at several $\mathrm{pH}$ values. The inset shows inverted test tube for following the gel development

et al. 2010). Figure $3 \mathrm{a}$ also shows that the typical surface plasmon resonance absorption band of NS particles at $\sim 400 \mathrm{~nm}$. The absorption bands of NS in $\mathrm{SF}_{\mathrm{L}} \mathrm{NSCs}$ and SFcNSCs solutions were recorded at $\sim 411$ and $397 \mathrm{~nm}$, respectively (Fig. 3b).

\section{Band gap energy calculations}

The band gap was estimated by Tacu's relationship:

$\alpha=\alpha_{0}\left(h v-E_{g}\right)^{n} / h v$,

where $\alpha$ is absorption coefficient, $h v$ is the photon energy, $\alpha_{\circ}$ is constant, $h$ is Blank's constant and $E_{g}$ is the optical band gap of the material. $n$ depends on the type of electronic transition and can be any value between $1 / 2$ and 3 (Tauc et al. 1966). The energy gaps of the samples have been determined by extrapolating the linear portion of the plots of $(\alpha h v)^{2}$ against $h v$ to the energy axis. Figure 4 indicates indirect electronic transition for all samples. The $E_{g}$ values were calculated to be $2.04,2.37,2.33,2.33$ and $2.169 \mathrm{eV}$ for SN, SFL, SFc, $\mathrm{SF}_{\mathrm{L}} \mathrm{NSCs}$ and SFcNSCs, respectively. The figure illustrates that the band gap of the composites slightly changed to higher values relative to the silver nanoparticles, which may be due to the polymeric nature of silk fibroin. Moreover, the silver nanoparticles' incorporation enhances the energy gap values of the pure silk fibroin. The differences have been attributed to variations in the stoichiometric of the synthesis, the impurities content, the crystalline size and the type of electronic transition (Hossain et al. 2008; Zinatloo-Ajabshir and Salavati-Niasari 2015).

\section{Fourier transform infrared spectroscopy}

FTIR spectra of $\mathrm{SF}_{\mathrm{C}}$ and $\mathrm{SF}_{\mathrm{L}}$ are shown in Fig. 5a. According to Cristian et al. (2005), the conformations of SF could be a random coil or beta structure and their characteristic bands are amide I, II, III and V modes. These 


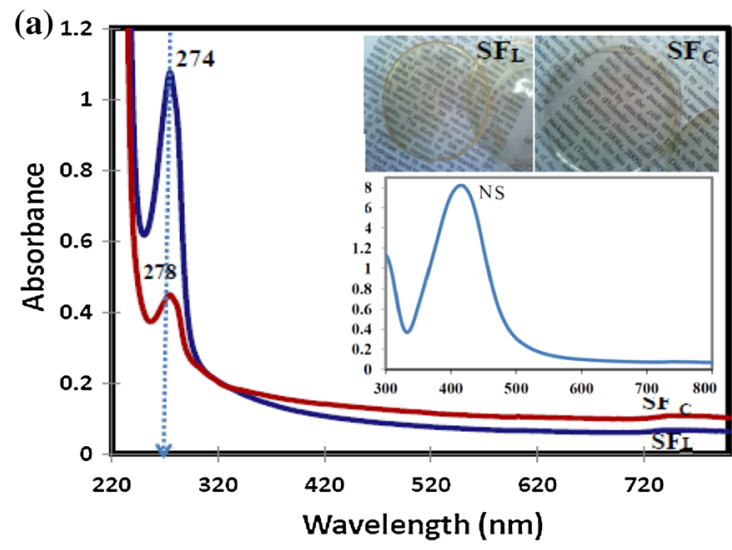

Fig. 3 UV-visible absorption spectra for a silk fibroin extracted by $\operatorname{LiBr}\left(\mathrm{SF}_{\mathrm{L}}\right)$, silk fibroin extracted by Ajisawa's reagent $\left(\mathrm{SF}_{\mathrm{C}}\right)$ and nanosilver solution (NS) and $\mathbf{b}$ composites with nanosilver chitosan

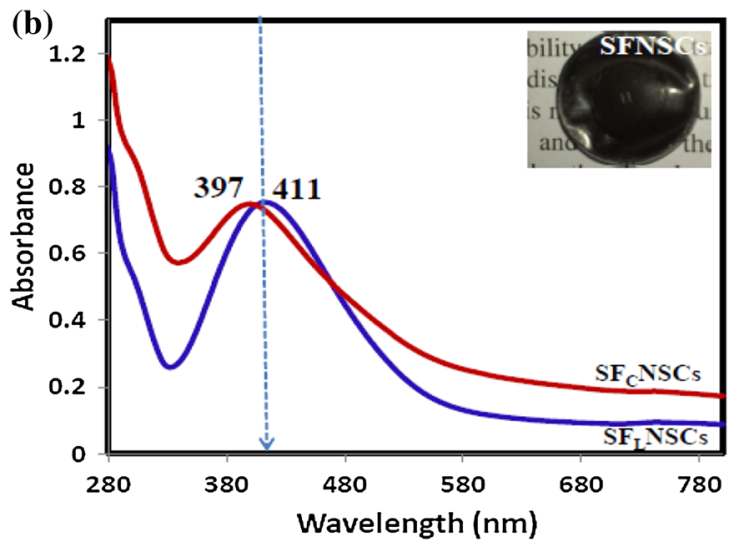

$\left(\mathrm{SF}_{\mathrm{L}} \mathrm{NSC}\right.$ and $\left.\mathrm{SF}_{\mathrm{C}} \mathrm{NSCs}\right)$. The inset pictures show corresponding films in (a) and composites (b) (a)

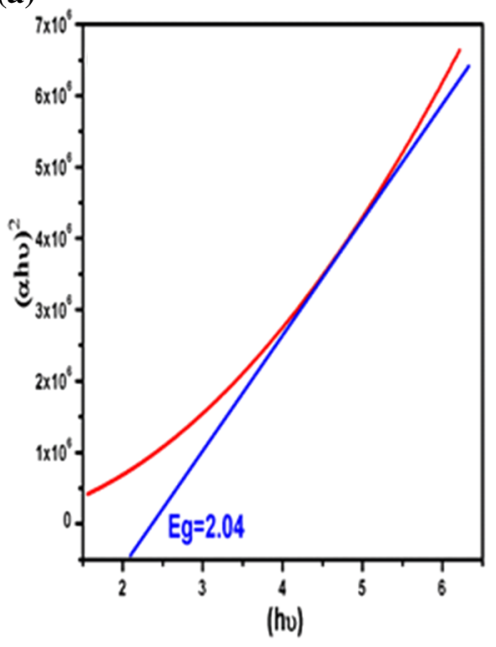

(d)

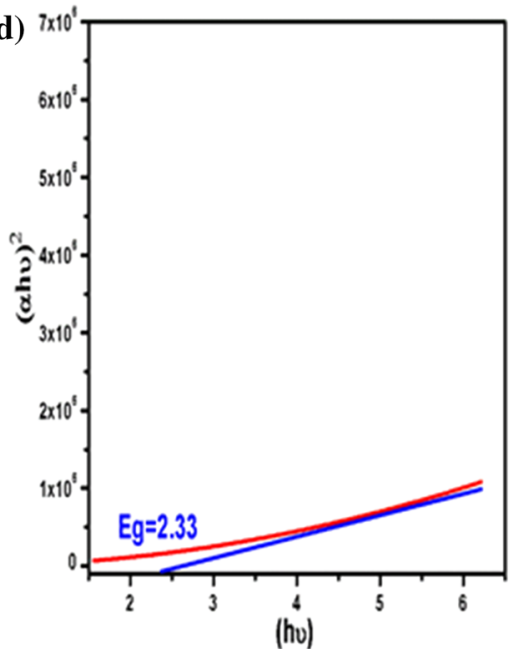

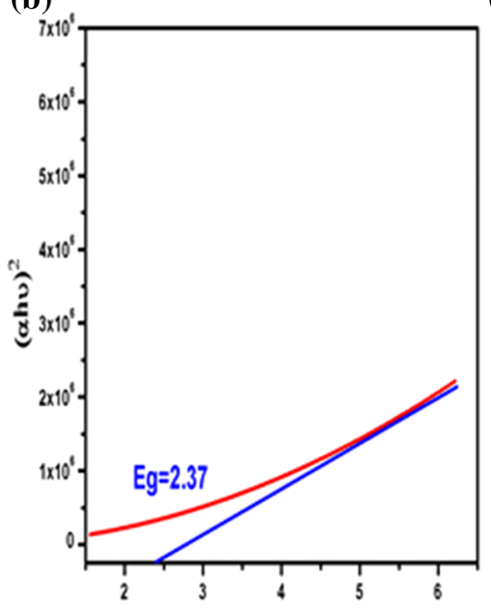

(ho) (c)

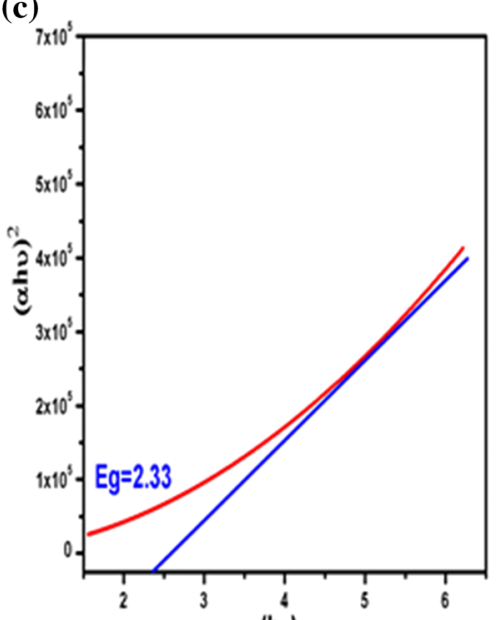

(hv)

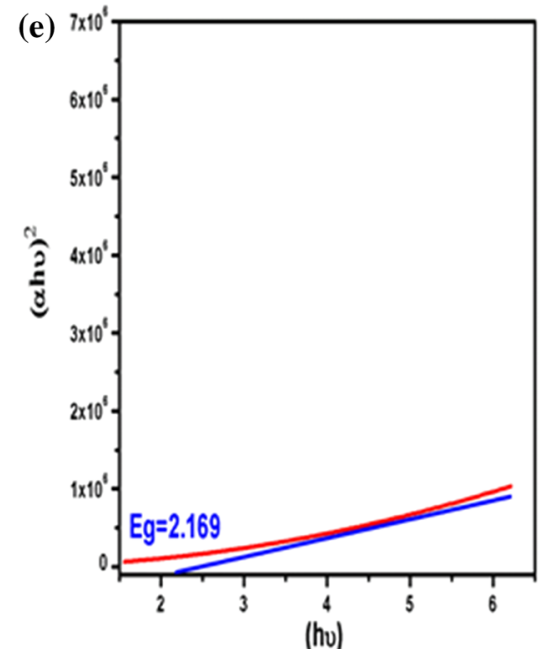

Fig. 4 Tacu's plot of the $(\alpha h v)^{2}$ as a function of photon energy $(h v)$ of a SN, b SF $F_{L}, \mathbf{c ~ S F _ { c }}, \mathbf{d ~ S F _ { L }} \mathrm{NSCs}_{\text {and }}$ e $\mathrm{SF}_{\mathrm{c}} \mathrm{NSCs}$ 

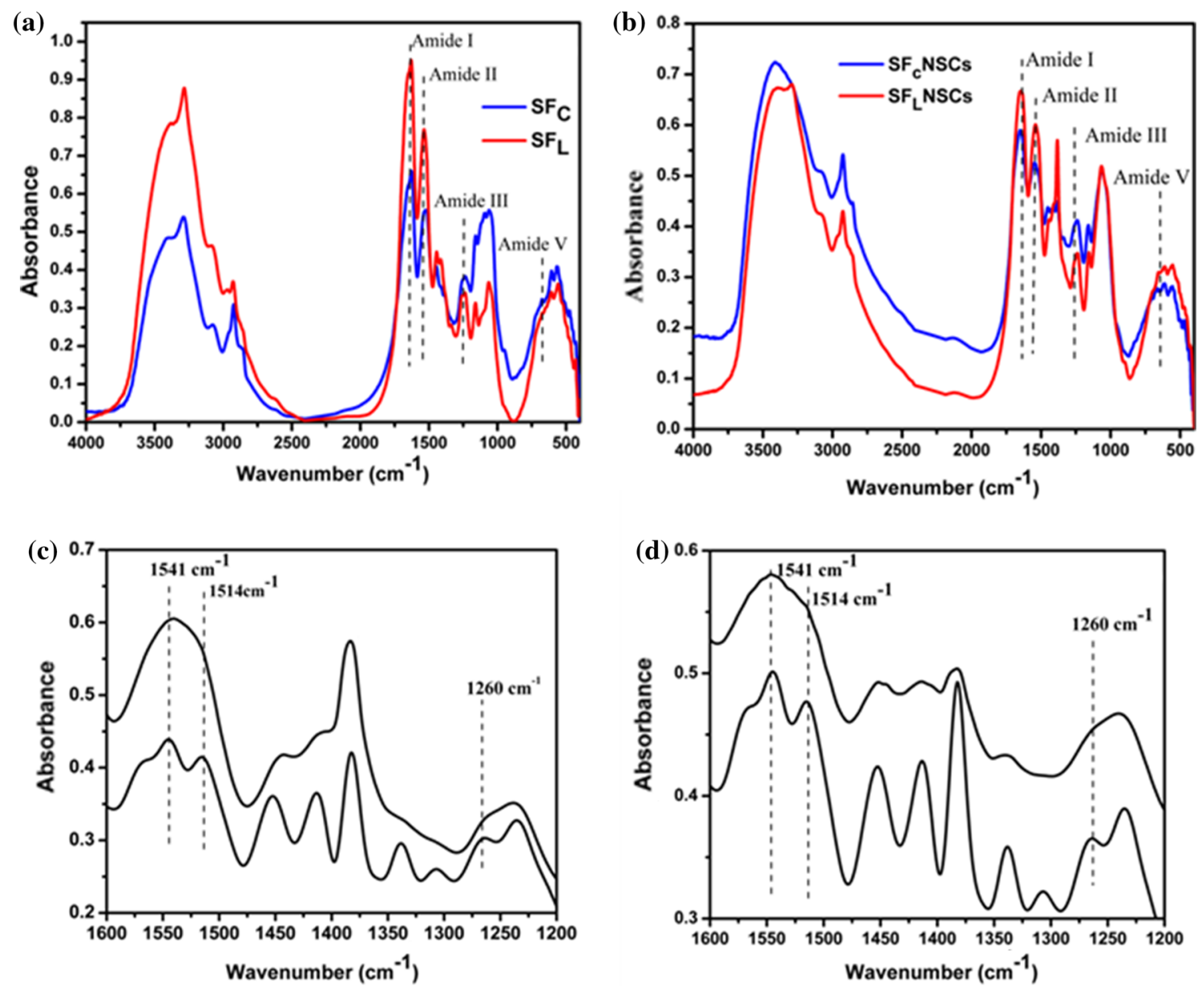

Fig. 5 Fourier transform infrared spectra of $\mathbf{a S F}_{\mathrm{L}}$ and $\mathrm{SF}_{\mathrm{C}}$. b FTIR spectra of composites $\mathrm{SF}_{\mathrm{L}} \mathrm{NSC}$ and $\mathrm{SF}_{\mathrm{C}} \mathrm{NSC}$. Corresponding deconvoluted FTIR Spectra $1200-1600 \mathrm{~cm}^{-1}$ of $\mathbf{c} \mathrm{SF}_{\mathrm{C}} \mathrm{NSCs}$ and $\mathbf{d} \mathrm{SF}_{\mathrm{L}} \mathrm{NSCs}$

Table 2 Comparison of band position shifts for the four amides in the random coil and $\beta$ structure of $\mathrm{SF}_{\mathrm{C}}, \mathrm{SF}_{\mathrm{L}}$ and composites $\mathrm{SF}_{\mathrm{L}} \mathrm{NSCs}, \mathrm{SF}_{\mathrm{C}} \mathrm{NSCs}$

\begin{tabular}{lllrrrr}
\hline Samples & Random coil structure & $\beta$ sheet & $\mathrm{SF}_{\mathrm{L}}$ & $\mathrm{SFc}$ & $\mathrm{SF}_{\mathrm{L}} \mathrm{NSCs}$ & $\mathrm{SF}_{\mathrm{C} N S C s}$ \\
\hline Amide I & $1650-1660$ & $1625-1640$ & 1633 & 1633 & 1655 & 1655 \\
Amide II & $1535-1545$ & $1515-1525$ & 1536 & 1541 & 1549 & 1547 \\
Amide III & 1253 & 1265 & 1252 & 1236 & 1244 & 1248 \\
Amid V & 650 & 700 & 609 & 616 & 616 & 606 \\
\hline
\end{tabular}

bands are assigned to $\mathrm{C}=\mathrm{O}$ stretching, $\mathrm{NH}$ deformation and $\mathrm{O}-\mathrm{C}-\mathrm{N}$ bending, respectively, while the amide $\mathrm{V}$ band arises due to crystallinity. Table 2 shows the assigned bands of Random coil or $\beta$ fold structure conformation of the silk fibroin and their corresponding composites.

The absorption bands prove the conformation of the protein is consistent with the absorption of amide I, II, III and V. Therefore, the silk fibroin extracted by either protocol has both $\alpha$ and $\beta$ structures in their composition. The increased amide I and II intensities in $\mathrm{SF}_{\mathrm{L}}$ indicated more water-soluble protein contents, while $\beta$ sheet assigned bands appeared more intense at $\mathrm{SF}_{\mathrm{C}}$ spectrum proving its higher crystallinity. The composites $\mathrm{SF}_{\mathrm{L}} \mathrm{NSCs}$ and $\mathrm{SF}_{\mathrm{C}-}$ NSCs exhibited shifts in the absorption bands of SF proving interaction between NS and NSCs (Fig. 5b).

\section{X-ray diffraction patterns (XRD)}

XRD spectra of $\mathrm{SF}_{\mathrm{L}}$ and $\mathrm{SF}_{\mathrm{C}}$ are shown in Fig. 6a. Silk fibroin protein peaks arising at $2 \theta=20^{\circ}$ and $25^{\circ}$ are attributed to the $\beta$-sheet crystalline structure of fibroin (Andiappan et al. 2013). The XRD peaks of $\mathrm{SF}_{\mathrm{C}}$ indicate more crystalline structure compared to those of $\mathrm{SF}_{\mathrm{L}}$ confirming and therefore, FTIR results. 

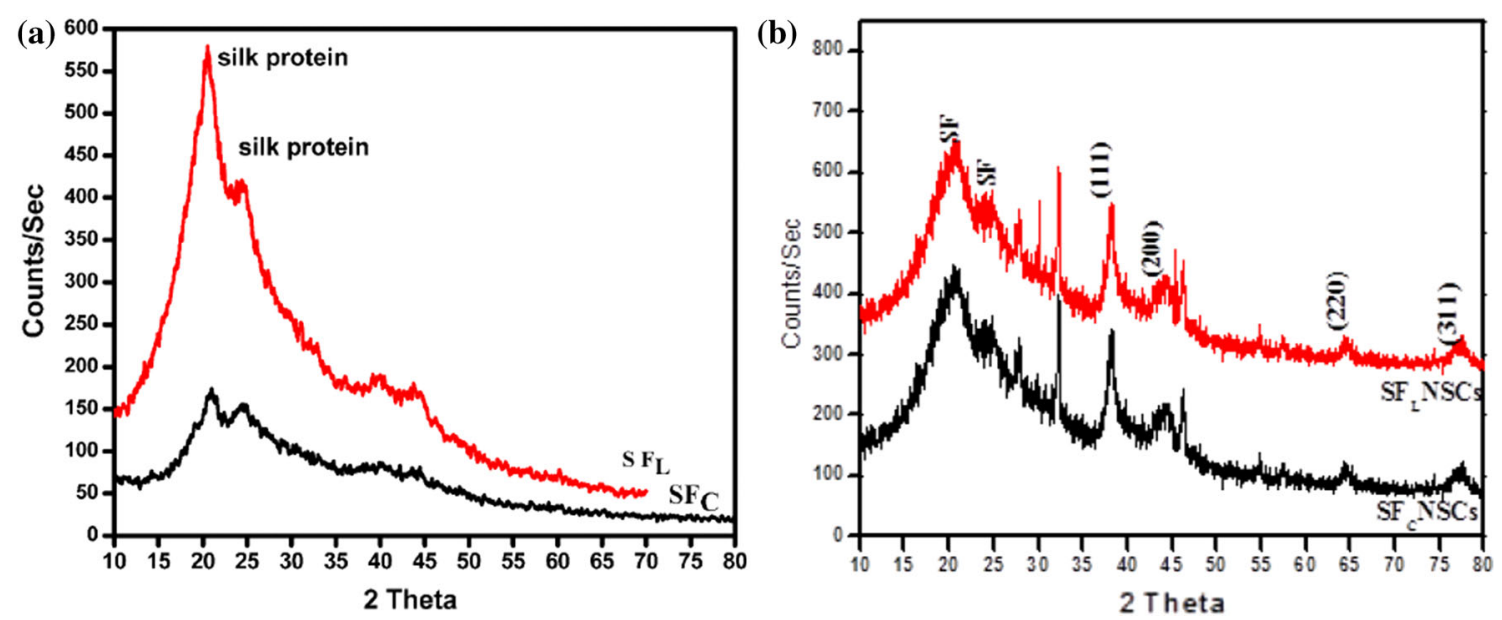

Fig. 6 XRD patterns of $\mathbf{a} \mathrm{SF}_{\mathrm{L}}$ and $\mathrm{SF}_{\mathrm{C}}$ and $\mathbf{b}$ characteristic $\mathrm{Ag}$ bands embedded in the silk composites recorded at 20 of $38.09^{\circ}, 43.92^{\circ}, 64.29^{\circ}$ and $77.51^{\circ}$ corresponding to $111,200,220$ and 311 planes for each of $\mathrm{SF}_{\mathrm{L}} \mathrm{NSCs}$ and $\mathrm{SF}_{\mathrm{C}} \mathrm{NSCs}$

For the composites SFNSCS (Fig. 6b), in addition to silk fibroin peaks, XRD pattern revealed four peaks corresponding to 4 diffraction facets of silver recorded at $2 \theta=38.09^{\circ}, 43.92^{\circ}, 64.29^{\circ}$ and $77.51^{\circ}$. The discernible peaks can be indexed to the planes (111), (200), (220) and (311), respectively, corresponding to face-centered cubic structure of silver according to JCPDS (No. 4-0783) which confirms the binding of NSCs to silk fibroin. A few intense additional and yet unassigned peaks were also noticed in the vicinity of the silver characteristic peaks. These sharp Bragg peaks might have resulted from some bioorganic compounds/protein(s) present in the composite (Pavani et al. 2013).

\section{Transmission electron microscope (TEM)}

Figure $7 \mathrm{a}$ shows the partially definite structure for silk fibroin extracted using the two protocols. After impregnation with chitosan silver nanoparticles, $\mathrm{SF}_{\mathrm{L}} \mathrm{NSC}_{\mathrm{S}}$ and $\mathrm{SF}_{\mathrm{C}} \mathrm{NSC}_{\mathrm{S}}$ reveal crystalline features. The selected area electron diffraction (SAED) patterns obtained for a representative composite have face-centered cubic (fcc) crystallographic structure. A number of well-dispersed nanoparticles which are spherical in shape and separated from each other with higher crystallinity are recorded for the $\mathrm{SF}_{\mathrm{C}} \mathrm{NSCs}$ composite which showed well-defined diffraction rings.

\section{Antimicrobial activity assessment}

The results represented in Fig. 8 showed that all the tested pellicles had a more acute effect on the gram-positive $S$. aureus cells compared to the gram-negative ones of $E$. coli and $P$. aeroginosa. This could be relied on the morphological and structural differences of the tested bacteria (Abdel-Fattah et al. 2014).
The histogram also shows that the films, developed using silk fibroin extracted by $\mathrm{LiBr}\left(\mathrm{SF}_{\mathrm{L}}\right)$, had a more intense antibiotic activity than those made using silk fibroin processed with Ajisawa's reagent. The former resulted in about $95 \%$ growth reduction while the latter resulted in only $67 \%$. This was probably due to the longer time necessary to completely dissolve the protein using the second protocol thus exposing the protein to a high temperature of $60{ }^{\circ} \mathrm{C}$ as well as mechanical stirring for a longer time, consequently, causing structural changes.

The massive destruction of the tested bacterial cells is clearly elucidated through SEM examination (Fig. 9a). Comparing the remaining percentages of silver nanoparticles, after the exposure of the $\mathrm{SF}_{\mathrm{L}} \mathrm{NSC}$ and $\mathrm{SF}_{\mathrm{C}} \mathrm{NSCs}$ composites to the bacteria, proves that more silver nanoparticles were involved in the bacterial invasion when $\mathrm{SF}_{\mathrm{L}}$ NSCs composites were used. Therefore, its higher antibacterial results are proved among all the tested pellicles.

\section{Discussion}

The present results proved that the decrease in the $\mathrm{pH}$ of the SF solutions favors the conformation transition from silk I to silk II which is related to the $\beta$-sheet formation. This is in agreement with the results of Nagarkar (2010) and could be explained by the fact that lowering the $\mathrm{pH}$ leads to a reduction in the negative charges due to the protonation of the amino acids. The later may promote protein refolding to a more ordered state stabilized by the hydrogen bonding between the chains and accompanied by an exclusion of water (Nagarkar 2010). The corresponding shorter gelation time of SFc (silk fibroin extracted by Ajisawa's reagent) could be explained through considering its structure. FTIR results revealed more insoluble beta 
Fig. 7 TEM micrographs showing the structure of silk fibroin a $\mathrm{SF}_{\mathrm{C}}, \mathbf{b} \mathrm{SF}_{\mathrm{L}}$, composites $\mathbf{c} \mathrm{SF}_{\mathrm{c}} \mathrm{NSCs}$ and d $\mathrm{SF}_{\mathrm{L}} \mathrm{NSCs}$ and corresponding SAED patterns

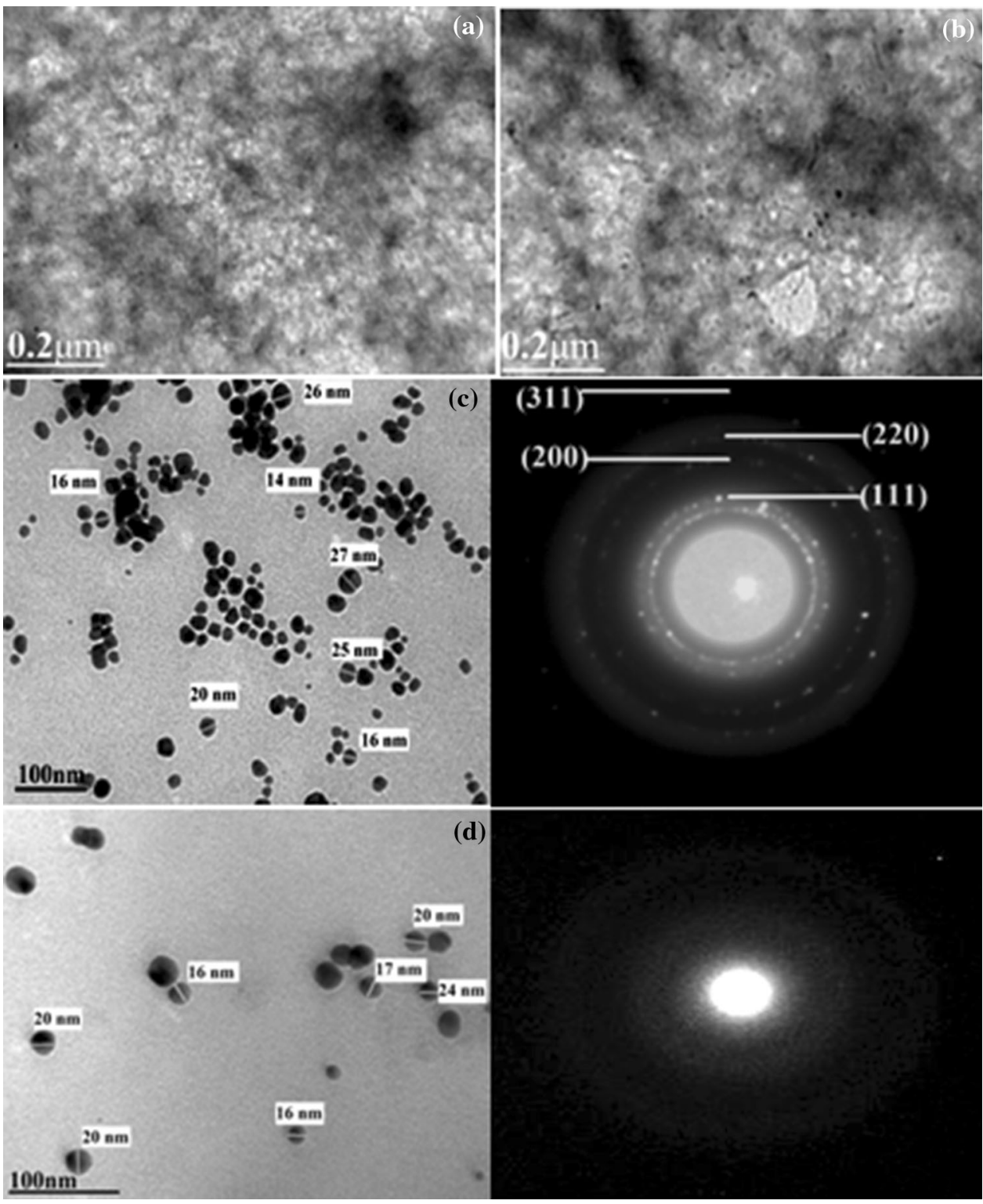

sheet in it compared to $\mathrm{SF}_{\mathrm{L}}$ (silk fibroin extracted by $\mathrm{LiBr}$ ) having more alpha helix. The $\beta$-sheet is comparatively more ordered and favors shorter gelation time.

The red shift of amide I absorption band of both composites from 1633 to around $1655 \mathrm{~cm}^{-1} \mathrm{Fig}$. $5 \mathrm{a}$, indicates blending with NSCs which induce further changes in SF protein structure. The peak at $1387 \mathrm{~cm}^{-1}$ recorded for composites $\mathrm{SF}_{\mathrm{C}} \mathrm{NSCs}$ and $\mathrm{SF}_{\mathrm{L}} \mathrm{NSCs}$ showed increased intensity for the first one indicating more binding of NSCs to silk fibroin inconsistency with the work of Ahmad et al. (2011).

Figure $5 \mathrm{~b}$ also shows that the stretching frequency $\mathrm{C}=\mathrm{O}$ band exhibited a blue shift in comparison to that of the free silk, denoting chelation. This shift was due to the reduction of the double bond character of the oxygen to the metal center in agreement with results reported (Reza and Morsali 2011). 
Fig. 9 SEM of the composite films with their EDAX on the selected area of SFF $_{\mathrm{L}} \mathrm{NSCs}$ and b $\mathrm{SF}_{\mathrm{C}} \mathrm{NSCs}$ after subjecting films to $S$. aureus, proving the massive destruction of bacterial cell walls especially for a $\mathrm{SF}_{\mathrm{L}} \mathrm{NSCs}$ composite with less nitrogen and silver contents (a)

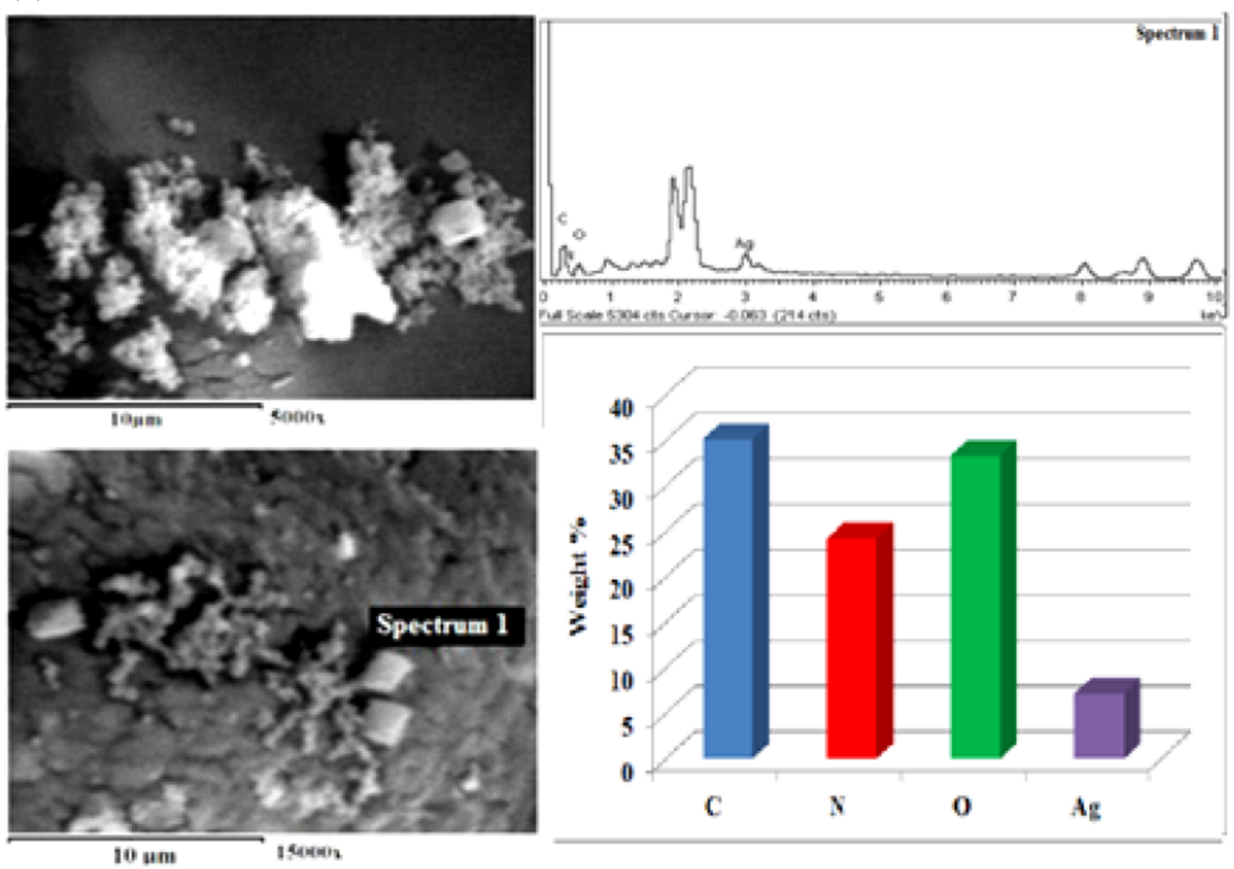

(b)

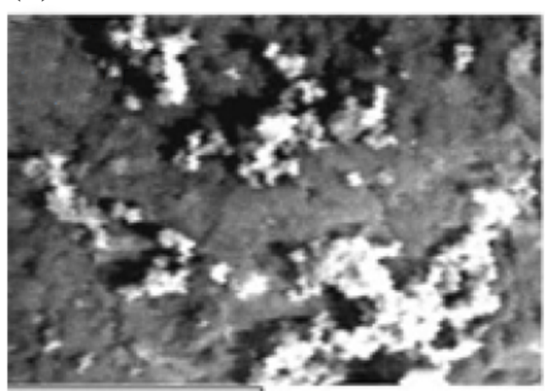

$10 \mu \mathrm{m}$

$5000 x$
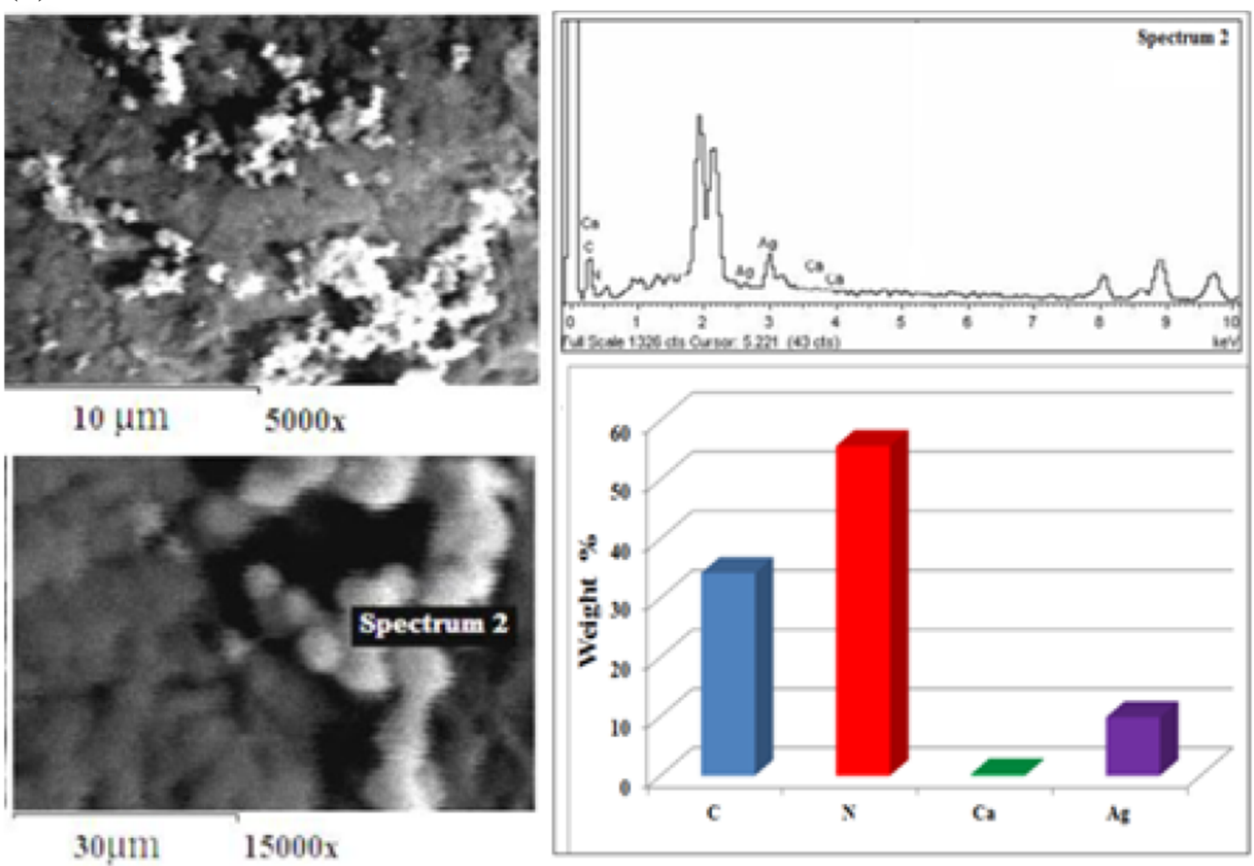

For a better comprehension of these results, a deconvolution of amide regions was performed, (Fig. 5). The amide I peak split into two small ones at 1650 and $1622 \mathrm{~cm}^{-1}$ where the last one indicates further increased $\beta$ sheet structure as a result of interaction between chitosan and silk fibroin. The amide II band is divided into two peaks at 1514 and $1541 \mathrm{~cm}^{-1}$ confirming, therefore, that the composite contains both random coil and $\beta$ sheet structures. The new peak appearing at $1260 \mathrm{~cm}^{-1}$ presented conformation transition from random coil to $\beta$-sheet of SF (Luangbudnark et al. 2012). These results lead to the fact that in addition to the chitosan role in protecting silver nanoparticles from agglomeration by enveloping them, it can also increase the transition from random coil to beta sheet of SF. 
The crystallite domain size was calculated from the width of the XRD peaks, assuming that they are free from non-uniform strains, using the Scherrer formula (Cullity 1978).

$D=\frac{0.9 \lambda}{\beta \cos \theta}$,

where $D$ is the average crystallite domain size perpendicular to the reflecting planes, $\lambda$ is the X-ray wavelength (1.5418 $\AA$ ), $\beta$ is the full width at half maximum (FWHM) and $\theta$ is the diffraction angle. Similar applications of Scherrer formula were used for assessing crystallite size domain for composites and nanoparticles (Salavati-Niasari et al. 2008, 2009; Zinatloo-Ajabshir et al. 2015; ZinatlooAjabshir and Salavati-Niasari 2014). The intensity of the Bragg reflections suggests strong X-ray scattering centers in the crystalline phase. It could possibly result from metalloproteins in XRD spectra of both $\mathrm{SF}_{\mathrm{C}} \mathrm{NSC}$ and $\mathrm{SF}_{\mathrm{L}} \mathrm{NSC}$ structures with an average particle size of 13-19 nm, respectively, with cubic shape. The obtained results denote that the incorporation of silver nanoparticles into the silk matrix does not affect its crystallite size.

The bactericidal effect shown in the histogram reveals that the $\mathrm{SF}_{\mathrm{L}}$ and $\mathrm{SF}_{\mathrm{C}}$ films, developed using silk fibroin extracts as a sole constituent, resulted in an obvious growth reduction of the tested strains, proving, therefore, that the silk fibroin itself has an effective antibacterial activity. These results have a logical explanation as the silk fibroin is the main constituent of silkworm cocoons which is initially meant to protect the pupae stage of silk worm in nature for a certain period of time. It would not be surprising that a kind of protection against bacteria is present in the fibers; otherwise, they would be biodegraded very fast and would not be able to protect the pupae till their complete development into mature butterflies and continue the life cycle of silkworm.

A comprehensive scientific explanation could be attributed to Pelegrini et al. (2008). The latter, in order to develop a novel approach to control common bacterial infections in plants, identified a number of defense peptides with antibacterial activities. Their characterization, using the amino acid sequencing method, clearly revealed that the glycine-rich protein was responsible for such activity. The mode of action of this protein seems to be via its interaction with the lipid layer of the bacterial cell wall surface leading to membrane permeability and consequent cell death (Pelegrini et al. 2008). On the other hand, many reports studied the structure of silk fibroin originating from the silkworm (B. mori). These studies showed that it is an insoluble protein formed of layers of antiparallel beta sheets. Although it is composed of 18 different amino acids, it has a high glycine concentration protein as it contains approximately $43 \%$ of its molecular

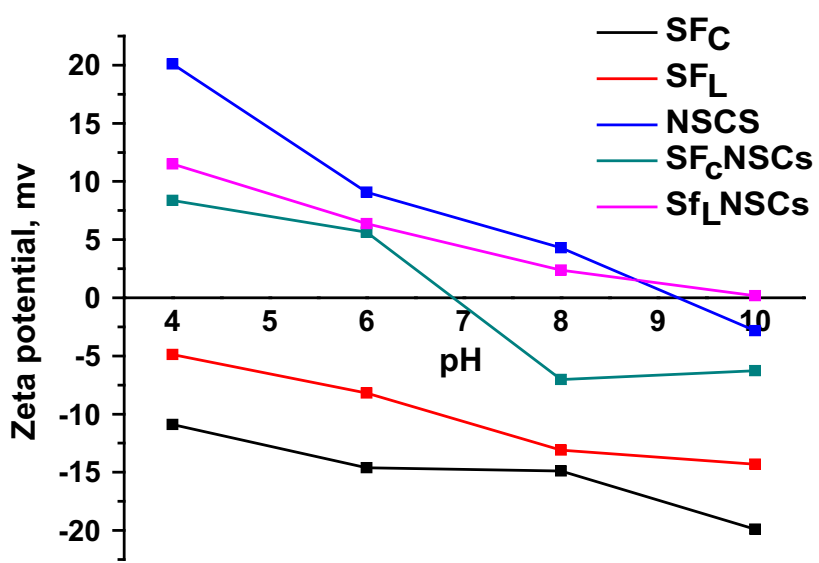

Fig. 10 Zeta potential values at several $\mathrm{pH}$ of all the prepared silk fibroin films $\mathrm{SFc}$ and $\mathrm{SF}_{\mathrm{L}}$, silver/chitosan (Ag6d3), and composites (SFcNSCs) and $\left(\mathrm{SF}_{\mathrm{L}} \mathrm{NSCs}\right)$

weight glycine which allows for tight packing of the sheets and, therefore, contributes to the silk's rigid structure and tensile strength. Therefore, we suggested that, similarly, the antibiotic activities of silk fibroin against the tested microorganisms could also be attributed to the presence of the high concentration of glycine in silk fibroin protein. This assumption was previously confirmed by the study of Ponnuvel and Yamakawa (2002). The latter found that the presence of such concentration of glycine in the silk fibroin extracted from silkworm was, among others, one of the main causes of its antimicrobial ability.

Moreover, the results in Fig. 5, illustrating the FTIR spectra of the dissolved silk fibroin, clearly elucidated the characteristic peaks for the random coil and $\alpha$-helix conformation (water-soluble fraction of the protein) as well as the $\beta$-sheet conformation (water-insoluble fraction of the protein) at the wavenumber of 1650 and $1235 \mathrm{~cm}^{-1}$, respectively (Wang et al. 2004; Huang et al. 2011). The present data showed that although both protein states coexist together in the silk fibroin samples obtained using either protocol, the protein in $\alpha$-helix was more marked when the $\mathrm{LiBr}$ reagent was used. TEM results additionally revealed that the SFcNSCs is more crystalline in nature than $\mathrm{SF}_{\mathrm{L}}$ NSCs. However, several studies showed that crystallization is directly dependent on the presence of more $\beta$ sheet structure. Therefore, the higher antibiotic activity of $\mathrm{SF}_{\mathrm{L}}$ films is explained, since only proteins in the soluble state could attack and penetrate the cell membranes of the tested microorganisms more efficiently.

The Zeta potential results (Fig. 10) revealed that, the NSCs possess a positive value with maximum of $20 \mathrm{mv}$ indicating partially stable nanoparticles, while pure SF possesses a negative zeta potential values ranging between -4.8 and $-19.9 \mathrm{mv}$. On the contrary, SF recorded positive 
values after its incorporation with NSCs. These results give more explanation for its higher antibacterial activity via electrostatic attraction between the negatively charged cell membranes of the bacteria and the positively charged composites. Therefore, Zeta potential is an essential parameter for the characterization of the stability of SF and SFNSCs suspensions.

\section{Conclusion}

Silk fibroin proved to be more readily dissolved in $\mathrm{LiBr}$ solution than in Ajisawa's reagent. Although both protocols eventually produced highly crystalline composites, $\mathrm{SF}_{\mathrm{C}}$ exhibited higher crystallinity with shorter gelation time. The optical energy calculated from all constructs indicated indirect electronic transitions. The regenerated silk fibroin exhibited antibacterial activity against the tested gram-positive and gram-negative bacteria. Moreover, reduction ability for the bacterial growth by SNCs composite was greatly enhanced by the inclusion of silk fibroin especially upon extraction with $\mathrm{LiBr}$ solvent system. The turbidity measurements showed that the bacterial inhibition increased up to $82 \%$ due to the combined effects of SN, Cs and SF. NSCs film has intermediate effect between both composites with that of $\mathrm{Li}$ imparting the highest effect. Such developed membranes could, therefore, be prospectively used as a commercial product for wound healing treatment. The SFNSCs composite advantages are 1) natural, having antibacterial activities. 2) Expected to be nonimmunogenic and could be processed easily into several forms. 3) Reproducible and could be directly applied in several biomedical applications. However, the darkness of the developed constructs could be controlled by optimizing the silver nanoparticles' concentration within the construct in a future work which will need further relevant bactericidal assessment too.

Acknowledgments The financial support of National Research Center, Cairo, Egypt, is appreciated. Prof. Dr. Ahmed I El-Diwany, Natural and Microbial Chemistry, National Research Center, Dokki, Cairo, is acknowledged gratefully for his kind support especially for antibacterial studies. Thanks are due to Prof. Dr. Assunta Borzacchiello Ph.D. Institute of Composite and Biomedical Materials-C.N.R and Interdisciplinary Research Centre on Biomaterials-University of Naples, Italy, for kindly supplying the dialysis membrane.

Open Access This article is distributed under the terms of the Creative Commons Attribution 4.0 International License (http://creativecommons.org/licenses/by/4.0/), which permits unrestricted use, distribution, and reproduction in any medium, provided you give appropriate credit to the original author(s) and the source, provide a link to the Creative Commons license, and indicate if changes were made.

\section{References}

Abdel-Fattah WI, Sallam AM, Nagwa A, Salama E, Ahmed M, Ghareib W (2014) Functionality, antibacterial efficiency and biocompatibility of nanosilver/chitosan/silk/phosphate scaffolds 1. Synthesis and optimization of nanosilver/chitosan matrices through gamma rays irradiation and their antibacterial activity. J Mater Res Express 1. doi:10.1088/2053-1591/1/3/035024

Acharya C, Kumar V, Sen R, Kundu S (2008) Performance evaluation of a silk protein based matrix for the enzymatic conversion of tyrosine to L-DOPA. J Biotechnol 3:226-233

Agarwal N, Hoagland D, Farris R (1997) Effect of moisture absorption on the thermal properties of Bombyx mori silk fibroin films. J Appl Polym Sci 63:401-410

Ahmad M, Yen M, Shameli K, Zobir M, Jye J (2011) Green synthesis and characterization of silver/chitosan/polyethylene glycol nano-composites without any reducing agent. Int J Mol Sci 12:4872-4884

Altman GH, Diaz F, Jakuba C, Calabro T, Horan RL, Chen J, Lu H, Richmond J, Kaplan DL (2003) Silk-based biomaterials. J Biomater 24:401-416

Andiappan M, Sundaramoorthy S, Panda N, Meiyazhaban G, Winfred SB, Venkataraman G, Krishna P (2013) Electrospun eri silk fibroin scaffold coated with hydroxyapatite for bone tissue engineering applications. J Progress Biomater 2-6. doi:10.1186/ 2194-0517-2-6

Autran P, Xavier C, Dulce G, Eduardo L (2010) Follow up of a model used for extraction fibroin by UV-VIS, XRD, FTIR and SEM/ EDS. In: Congress of artificial organs and biomaterials

Chen X, Knight DP, Shao Z, Vollrath F (2001) Regenerated Bombyx silk solution studied with rheometry and FTIR. J Polym. 42:09969-09974

Chen P, Songa L, Liu Y, Fang Y (2007) Synthesis of silver nanoparticles by $\gamma$-ray irradiation in acetic water solution containing chitosan. J Radiat Phys Chem 76:1165-1168

Cristian C, Bridges C, Ha S, Alan E (2005) Conformational changes induced in Bombyx mori silk fibroin by cyclodextrin inclusion complexation. J Macromol 38:5640-5646

Cullity BD (1978) Elements of X-ray diffraction. Wesley Publishing Company Inc, USA

Dalpra I, Freddi G, Minic J, Chiarini A, Armato U (2005) De novo engineering of reticular connective tissue in vivo by silk fibroin nonwoven materials. J Biomater 26:1987-1999

Fini M, Motta A, Torricelli P, Giavaresi G, Aldini N, Tschon M, Giardino R, Migliaresi C (2005) The healing of confined critical size cancellous defects in the presence of silk fibroin hydrogel. J Biomater 26:3527-3536

Haider Z, Hirabayashi K, Arai M (1992) Effect of pH on silk fibroin gelation. J. Sen'i Gakkaishi 48:141-144

Hanawa T, Watanabe A, Tsuchiya T, Ikoma R, Hidaka M, Sugihara M (1995) New oral dosage form for elderly patients: preparation and characterization of silk fibroin gel. J Chem Pharm Bull 43:284-288

Hossain F, Sheppard L, Nowotony J, Murch G (2008) Optical properties of anatase and rutile titanium dioxide: ab initio calculations for pure and anion doped material. J Phys Chem Solids 69:1820-1828

Huang JW, Zhang F, Zuo BQ, Fan ZH, Zhang HX (2011) Preparation and characterization of electrospun silk fibroin-based tubular scaffolds. J Adv Mater Res 175-176:197-201

Inoue L, Tanaka K, Arisaka F, Kimura S, Ohtomo K, Mizuno S (2000) Silk fibroin of B. mori is secreted, assembling a high molecular mass elementary unit consisting of H-chain, L-chain, and P25, with a 6:6:1 molar ratio. J Biol Chem 275:40517-40528 
Liang C, Hirabayashi K (1992) Improvement of the physical properties of fibroin membranes with sodium alginate. J Appl Polym Sci 45:1937-1943

Luangbudnark W, Viyoch J, Laupattarakasem W, Surakunprapha P, Laupattarakasem P (2012) Properties and biocompatibility of chitosan and silk fibroin blend films for application in skin tissue engineering. J Sci World 2012:1-10

Mathur A, Tonelli A, Rathke T, Hudson S (1997) The dissolution and characterization of Bombyx mori silk fibroin in calcium nitratemethanol solution and the regeneration of films. J Biopolym 42:61-74

Matsumoto K, Uejima H (1997) Regenerated protein fibers I. Research and development of a novel solvent for silk fibroin. J Polym Sci Polym Chem 35:1949-1954

Matsumoto K, Uejima H, Sano Y, Sumino H (1997) Regenerated protein fibers. 2. Viscoelastic behaviour of silk fibroin solution. J Polym Sci Polym Chem 35:1955-1959

Meinel L, Fajardo R, Hofmann S, Langer R, Chen J, Snyder B, Vunjak-Novakovic G, Kaplan D (2005) Silk implants for the healing of critical size bone defects. J Bone 37:688-698

Motta A, Fambri L, Migliaresi C (2002) Regenerated silk fibroin films: thermal and dynamic mechanical analysis. J Macromol Chem Phys 203:1658-1665

Nagarkar SP (2010) Gelation of regenerated fibroin. Ph.D. thesis, National Chemical Laboratory, Pune, India

Pavani K, Gayathramma K, Banerjee A, Suresh S (2013) Phytosynthesis of silver nanoparticles using extracts of Ipomoea indica flowers. Am J Nanomater 1:5-8

Pelegrini P, Andre M, Luciano P, Rachel C, Santos D, Fabio T, Paula D, Carlos J, Eliane F, Robert N, Octavio L (2008) Identification of a novel storage glycine-rich peptide from guava (Psidium guajava) seeds with activity against Gram-negative bacteria. J Pept 29:1271-1279

Ponnuvel KM, Yamakawa M (2002) Immune responses against bacterial infection in Bombyx mori and regulation of host gene expression. J Curr Sci 83:447-454

Reza A, Morsali A (2011) Synthesis and properties of silk yarn containing $\mathrm{Ag}$ nanoparticles under ultrasound irradiation. J. Ultrason Sonochem 18:282-287

Rujiravanit R, Kruaykitanon S, Alexander M, Tokura S (2003) Preparation of crosslinked chitosan/silk fibroin blend films for drug delivery system. J Macromol Biosci 3:604-611
Salavati-Niasari M, Davar F, Mazaheri M (2008) Synthesis of $\mathrm{Mn}_{3} \mathrm{O}_{4}$ nanoparticles by thermal decomposition of a [bis(salicylidiminato)manganese(II)] complex. J Polyhedron 27:3467-3471

Salavati-Niasari M, Dadkhah M, Davar F (2009) Pure cubic $\mathrm{ZrO}_{2}$ nanoparticles by thermolysis of a new precursor. J Polyhedron 28:3005-3009

Salvador D, Daniel V, Luis M, José L, Abel Lozano-Péreza A (2013) Influence of the protocol used for fibroin extraction on the mechanical properties and fiber sizes of electro spun silk mats. J Mater Sci Eng C 33:1945-1950

Santin M, Motta A, Freddi G, Cannas M (1999) In vitro evaluation of the inflammatory potential of the silk fibroin. J Biomed Mater Res 46:382-389

Simmons A, Michak C, Jelin Ski L (2006) Molecular orientation and two component nature of the crystalline fraction of spider dragline silk. J Sci 271:84-87

Sofia S, McCarthy M, Gronowicz G, Kaplan D (2001) Functionalized silk-based biomaterials for bone formation. J Biomed Mater Res 54:139-148

Sonthisombat A, Peter T (2004) Silk: queen of fibers. Ph. D. Thesis, the former, RIT, Thailand, the later, The University of Leeds

Sun Y, Shao Ma ZM, Hu P, Liu Y, Yu T (1997) Acrylic polymer-silk fibroin blend fibers. J Appl Polym Sci 65:959-966

Tauc J, Grigorovici R, Vancu A (1966) Optical properties and electronic structure of amorphous germanium. J Phys Status Solidi B 15:627-637

Vepari C, Kaplan D (2007) Silk as a biomaterial. J Prog Polym Sci 32:991-1007

Wang M, Jin HJ, Kaplan DL, Rutledge GC (2004) Matrix metalloproteinases and their clinical applications in orthopedics. J Macromol 37:6856-6864

Zinatloo-Ajabshir S, Salavati-Niasari M (2014) A sonochemicalassisted synthesis of pure nanocrystalline tetragonal zirconium dioxide using tetramethylethylenediamine. J Int J Appl Ceram Technol 11:654-662

Zinatloo-Ajabshir S, Salavati-Niasari M (2015) Novel (poly ethylene glycol)-assisted synthesis of praseodymium oxide nanostructures via a facile precipitation route. J Ceram Int 41:567-575

Zinatloo-Ajabshir S, Salavati-Niasari M, Hamadaniana M (2015) Praseodymium oxide nanostructures: novel solvent-less preparation, characterization and investigation of their optical and photocatalytic properties. J RSC Adv 5:33792-33800 